SECCIÓN III * TEMA CENTRAL

Liderazgo carismático y populismo 



\title{
El liderazgo político en democracias de baja institucionalización (el caso del peronismo en la Argentina)*
}

\author{
María Matilde Ollier**
}

\begin{abstract}
Resumen
Dada la baja institucionalización del peronismo, el artículo argumenta que su fortaleza se debe a que el liderazgo estructura al peronismo como organización política al tiempo que funda su legitimidad última en el voto ciudadano. Para desarrollar su tesis el artículo, primero, describe cómo Perón ejerce su liderazgo carismático y arma el modelo peronista y, segundo, analiza los liderazgos carismáticos de situación de Carlos Menem y Néstor Kirchner acorde al modelo peronista reciclado a los nuevos tiempos. Finalmente, pone a prueba la hipótesis exploratoria demostrando cómo, entre 1983 y 2007, los liderazgos justicialistas locales de la franja territorial más decisiva de la Argentina por su peso electoral, el Conurbano Bonaerense, se alinean con el liderazgo máximo.
\end{abstract}

Palabras clave: Liderazgo presidencial, provincial y local - liderazgo partidario - organización política - peronismo - imbricación.

\begin{abstract}
Given Peronist weak institutionalization, the paper argues that Peronist strength is due to the fact that leadership organizes Peronism as political force, and in the end, such leadership is legitimated by citizen suffrage. To develop this interpretation, the article, first, describes how Perón's charismatic leadership leads and builds Peronist organization; and second, it analyzes how Menem and Kirchner's charismatic leadership of situation guide the recycled Peronist model. Finally, the article tests the tentative hypothesis by demonstrating how Peronist local leadership from Conurbano Bonaerense, the Argentinean most decisive territorial portion in electoral terms, align with Peronist top leadership.
\end{abstract}

Keywords: Presidential, provincial and local leadership - partisan leadership - political organization - peronism - overlapping.

* Quiero agradecer los atinados e inteligentes comentarios realizados por Ricardo Gutiérrez y Aníbal Pérez Liñán, que me ayudaron a revisar el paper presentado en IPSA Chile, 2009.

** Es Doctora en Ciencia Política por la Universidad de Notre Dame (USA), Máster en Ciencias Sociales (FLACSO) y profesora de Historia (UBA). 


\section{INTRODUCCIÓN}

Argentina posee un presidencialismo fuerte (Mainwaring y Shugart, 2002) asentado en una débil institucionalización tanto del régimen democrático (O'Donnell, 1995) como del sistema partidario (Cavarozzi, 2002). Desde el regreso de la democracia, en 1983, estos rasgos lejos de debilitar al peronismo en términos de representatividad, gobernabilidad y estabilidad, lo han mantenido e incluso reforzado ${ }^{1}$. El artículo busca la explicación de esta fortaleza a partir de explorar la siguiente hipótesis: el liderazgo estructura al peronismo como organización política, fundando su legitimidad última en el voto ciudadano, en la competencia interna y/o en la elección general. Entiendo por "estructura" el papel del liderazgo en organizar las relaciones horizontales y verticales que se despliegan en su interior. Si bien numerosos autores han intentado develar aquel enigma peronista ${ }^{2}$, incluso reconociendo la relevancia del liderazgo, todavía no se ha procurado una explicación común para Juan Perón, Carlos Menem y Néstor Kirchner.

Al frente del Estado, e instaurado por Perón, el justicialismo ensambla liderazgo presidencial y jefatura partidaria (formal o informal). Esta imbricación favorece el ejercicio concentrado del poder presidencial permitiendo, a su vez, que el peronismo emerja con diferentes caras (del neoliberalismo al populismo económico) que simbolizan las de sus liderazgos circunstanciales. El ejercicio del poder concentrado hacia adentro del peronismo tiende entonces a reproducirse desde el liderazgo presidencial hacia el conjunto del régimen democrático.

Sin embargo, la distinción entre liderazgo eterno y temporal constituye la diferencia entre el peronismo original y el que emerge luego de la tercera ola de democratización. En el primero, el líder tiene un estatus suprapolítico en tanto existe un tabú que impide a la dirigencia partidaria cuestionar el liderazgo de Perón o pensar en una sucesión antes de su muerte. Solamente con el caudillo en el exilio algunos jefes sindicales y políticos se atrevieron a desafiar ese tabú, aunque manteniendo cierta ambigüedad (Ollier, 2005). Menem y Kirchner, en cambio, son un primus inter pares. Desafiarlos puede acarrear dificultades políticas, pero no hay un imaginario sobre su estatus superior, quedando claro para la cúpula que serán reemplazados. Así, mientras la segunda reelección de Menem resulta inviable, ningún peronista le hubiera cuestionado ese "derecho" a Perón.

1 Desde 1983, ningún presidente peronista electo por la ciudadanía salió anticipadamente del gobierno (estabilidad). A su vez, el partido mantiene una masa de votantes del $40 \%$ (representatividad) y se le atribuye capacidad de gobierno (gobernabilidad). Asistimos al record justicialista en el gobierno nacional y en los provinciales (Jones, 2002).

2 Han dado cuenta del mismo, desde la historia: McKinnon (2002), Torre (1983, 1990, 2002), Waldman (1981), Zanatta (1999), Buchrucker (1986), Navarro (2002), Barry (2009); sobre la proscripción y el exilio: Amaral y Plotkin (2005), James (1990), Ollier (2005), Sigal y Verón (1986); desde la renovación post-1983: Arias (2002, 2004), De Ipola (1987), Gutiérrez (2003), Levitsky (2003), McGuire (1997), Palermo y Novaro (1996), Sidicaro (2002) y Torre (1999). 
Si el liderazgo constituye una parte central de la explicación sobre el peronismo, la otra reside en su morfología. Ambas resultan inseparables. El clásico trabajo de Panebianco (1990) permite ubicar el justicialismo en una perspectiva teórica que combina los tres modelos de partido que confluyen en su fundación: carismático, de masas y de gobierno. Semejante amalgama ha pervivido reciclada a los nuevos tiempos, bajo distintos liderazgos temporales y con un sesgo de partido profesional-electoral capaz de alimentar su histórica fortaleza organizativa.

Para intentar corroborar la hipótesis exploratoria, el artículo se compone de tres secciones. La primera describe cómo Perón (1946-1955) construye su liderazgo y, al mismo tiempo, la organización peronista. Para ello recurro a los modelos de partidos mencionados. La segunda sección analiza el peronismo, luego de 1983, a partir de entender su reorganización y la construcción de los liderazgos de Carlos Menem (1988-1999) y de Néstor Kirchner (2003-2007). Esta lectura del peronismo se realiza sobre fuentes secundarias basadas en investigaciones empíricas, capaces de probar que los diferentes liderazgos peronistas encierran igual concepción del ejercicio del poder, clave para comprender cómo éste estructura al peronismo verticalmente, al tiempo que permite las disputas horizontales por debajo de su máximo jefe, cuando éste existe, y entre los posibles competidores cuando la jefatura se halla vacante. La tercera sección pone a prueba la hipótesis, Ilevando a cabo un trabajo empírico que muestra la conexión vertical entre el liderazgo nacional temporal, no exento de disputas horizontales para alcanzarlo, y el resto de los liderazgos intermedios, es decir, gobernadores e intendentes, entre 1983 y 2007, en el Conurbano Bonaerense, la franja territorial más decisiva de la Argentina por su peso electoral.

\section{PERSPECTIVA HISTÓRICO-EMPÍRICA: EL LIDERAZGO CARISMÁTICO DE JUAN PERÓN Y EL MOLDE PERONISTA}

Cuando se analiza el liderazgo de Perón, siempre se remite a su sesgo carismático plasmado en la relación líder-masa. Raramente se estudia cómo Perón ejerce el poder y construye la organización peronista, pues su liderazgo en realidad halla dos destinatarios: el pueblo beneficiario de sus políticas y los dirigentes justicialistas; estos últimos imprescindibles para el ejercicio de su poder, al ser junto a Perón los responsables por la organización (y funcionamiento) del peronismo. De este modo, el movimiento político convertido en una herramienta de poder y de gobierno le permite al jefe peronista concentrar poder personal. En este aspecto del liderazgo de Perón, replicado por sus herederos, Carlos Menem y Néstor Kirchner, radica la llave para comprender la actual fortaleza peronista en términos de representación, gobernabilidad y estabilidad ${ }^{3}$.

3 El justicialismo posee algunos rasgos diferentes a la UCR, el otro partido relevante de la configuración partidaria. Si bien éste no es el lugar para una comparación, a los efectos de potenciar la descripción del PJ, es preciso tener en cuenta que la UCR se distingue en algunos aspectos de su construcción histórica (Rock, 2001; Persello, 2007), su trayectoria y sus divisiones (Smulovitz, 1988) que impactan en su desempeño luego de 1983 (Tedesco, 1999; Pucciarelli, 2006). La UCR nace a fines del siglo XIX como un grupo de la élite que confronta con el statu quo. Si bien su fundador, Hipólito Irigoyen, lo organiza como partido de masas una vez en el poder (Halperín 
Perón construye inicialmente su liderazgo desde el Estado, como Secretario de Trabajo y Previsión, Ministro de Guerra y Vicepresidente de la Nación de un gobierno militar (1943-1946)4 Elegido presidente por el voto popular, se vuelve el heredero del régimen al sacar ventaja del temor de la élite a una revolución social y presentarse como el hombre capaz de contener a las clases populares. Arma una coalición electoral de obreros, sectores del radicalismo y del conservadurismo, la Iglesia Católica, las Fuerzas Armadas y franjas del nacionalismo; coaliga entonces posibles adversarios: las Fuerzas Armadas y la clase obrera.

Perón consigue la adhesión de los trabajadores merced a su carisma plasmado en un discurso sencillo y en políticas públicas destinadas a él. En vez de prometer a los humildes un paraíso inalcanzable, al estilo de sus opositores socialistas y comunistas, Perón les habla de manera simple y les brinda beneficios concretos (James, 1990). Su habilidad para conectar con las clases populares marca su triunfo de 1946; así su popularidad funda su legitimación para: (1) disciplinar a sus propios seguidores, llevando a cabo la organización peronista, (2) sujetar el sindicalismo al Estado, vía el monopolio de la representación y la centralización de los sindicatos, contra los sectores obreros que proponen mantener la autonomía (Torre, 1990; Doyon, 1990) y (3) subordinar a su voluntad la Corte Suprema y el Parlamento ${ }^{5}$.

Utilizando los datos provistos por McKinnon (2002), aunque no siguiendo su interpretación, es factible analizar las reglas de construcción del liderazgo de Perón dentro de su fuerza política. Él lidera la unificación del Partido Laborista (formado por sindicatos) y la Unión Cívica Radical Junta Renovadora, en el Partido Único de la Revolución. Sin que su intervención se note, arma un partido "encuadrado", es decir, centralizado y subordinado a su persona, pese al conflicto inicial de intereses entre ambos grupos. Su liderazgo carismático conlleva, entonces, un proceso de concentración del poder que estructura la organización política.

Desde mi perspectiva, cuatro hitos prueban la forma que Perón construye paralelamente un liderazgo concentrado en su persona y una organización vertical, el Partido Único. El primero radica en la composición de la Junta Ejecutiva Nacional (JEN), conductora de la organización partidaria, que no responde estrictamente a la relación de fuerzas en juego, pues la presencia de "oficialistas" pone una cuña entre las dos tendencias más representativas (renovadores y laboristas) obligándolas a compartir el organismo con "los leales". En esta instancia dos datos explican la influencia decisiva de Perón. El primero remite al modo de

Donghi, 2000), cumple su mandato constitucional sin forzar un nuevo período, con lo cual tiene un sucesor en vida. Esto favorece una división en la UCR que, bajo la consigna se rompe pero no se dobla, ha llevado al partido a un faccionalismo que ha perjudicado su performance. La UCR carece del valor de la unidad propia del peronismo. Su funcionamiento prioriza atender los asuntos partidarios antes que alcanzar el éxito electoral, por lo cual gira alrededor de sus disputas y acuerdos internos, mientras el PJ procura satisfacer las demandas de los votantes que constituyen la legitimidad última de sus líderes y la posibilidad de acceder al Estado. Así la crisis del 2001 que golpea fuertemente a la UCR dio como resultado un candidato a presidente producto de su encierro, expresado en el 2,3\% de los votos obtenidos. En ese proceso otros postulantes provenientes de la UCR rompen con el partido (Ricardo López Murphy y Elisa Carrió) y logran más votos.

4 Para ver las dotes de Perón para construir su liderazgo previa llegada a la presidencia, Potash (1980).

5 Los miembros de la Corte Suprema sufren juicio político y son reemplazados por amigos del gobierno. Además Perón controla el Senado, cuenta con 109 diputados sobre 158 y con trece provincias sobre catorce. 
intervención de Perón, que se presenta como un agente que apacigua las rencillas internas para contrarrestar la facciosidad. Siendo ésta un problema que la política argentina acarrea desde el comienzo de la democracia en 1916, Perón ofrece su liderazgo como la posibilidad y el motivo de la unidad de la organización y en consecuencia de su fortaleza y perdurabilidad. Segundo, la escasa resistencia a sus órdenes, observada desde el comienzo (McKinnon, 2002: 49). Si desobedecer resulta entonces atentar contra la unidad, la voluntad de Perón configura la garantía de la organización. De este modo, liderazgo y organización devienen imbricados desde el comienzo en el imaginario y la práctica peronista.

El segundo hito, el reemplazo de la JEN por el Concejo Superior del Partido, trae aparejado el aumento de la franja oficialista (Ibíd: 86). El tercero lo constituyen dos medidas cruciales, tomadas por el Congreso General Constituyente de 1947: la prohibición del disenso (Ibíd: 97) y la atribución al líder de facultades superiores a las ejercidas por los organismos partidarios (Artículo 8 de la Carta Orgánica, Ibíd: 98). Así concluye la unificación partidaria sujeta a la autoridad del líder. El cuarto hito encierra, en 1949, la retirada del Concejo Superior de los hombres de la primera hora y el arribo de los advenedizos, más leales a la organización (Ibíd: 138), esto es, a Perón. La sustitución culmina un proceso promovido por Perón que finaliza con la identificación de la organización con el líder y de éste con el pueblo. Según McKinnon, el arbitraje de Perón en esta última etapa aparece mediado por dirigentes intermedios. Sin embargo, su intervención, según ella, nunca fue excesivamente notoria. Por lo tanto, desde mi perspectiva, Perón organiza su movimiento (y tercia) conduciendo vía sus dirigentes intermedios, pues su presencia en el "terreno" arriesga en convertirlo en parte de una facción. De este modo se reserva la última palabra en cada conflicto al colocarse por encima de las rencillas internas.

La autora reconoce que la última etapa representa "un Perón cuyo poder carismático ha aumentado, en gran parte debido al aumento de su caudal de votos, el origen y la garantía en última instancia de su legitimidad" (Ibíd: 142). Esto será así para siempre en el peronismo: la jefatura legalizada por los votos ciudadanos se ejerce de manera concentrada y personalizada, hacia adentro de la organización y hacia el régimen político. En esta segunda dirección comete un error político irreparable cuando, a tres años de su segundo mandato, avanza en ese proceso al intentar peronizar la nación, incluida la Iglesia Católica. Perón cae, entonces, víctima de un golpe de Estado 6 .

La "organización" deviene central para entender la concepción del liderazgo de Perón, quien cree que el éxito de las Fuerzas Armadas yace en ella, pero la organización permite la unidad, entendida por él, como verticalidad ${ }^{7}$. En la Asamblea Nacional Peronista de 1949 Perón expone la importancia de la organización, pues si las escisiones se profundizan pueden conducir al partido a la ruptura. De ahí su manera de evitar la facciosidad interviniendo en los

6 Perón ve en el catolicismo el lugar del antiperonismo (Caimari, 2002). Waldman (2009) califica de autoritarismo la segunda presidencia.

$7 \quad$ Para un análisis de la doctrina justicialista, Buchrucker (1986). 
conflictos a través de los mediadores. De este modo las disputas no dividen ni comprometen su lugar de jefe máximo, garantía última de la unidad.

Ahora bien, si el lugar encumbrado de Perón como jefe del movimiento se vincula estrechamente al éxito de su gestión al frente de la Casa Rosada, esto lleva a otra lección: alcanzar el gobierno garantiza al jefe el mantenimiento de la organización. En consecuencia, líder/organización/masa/votos/gobierno/Estado constituyen componentes inseparables del diseño peronista. El líder, como Presidente de la Nación, ejerce un poder concentrado hacia adentro del movimiento y hacia otras instituciones (sindicatos, Fuerzas Armadas, gobernadores, Parlamento, Corte), ambas instancias de centralización del poder en manos del líder resultan inherentes a la gobernabilidad peronista.

El estilo de liderazgo de Perón se mantiene, con las diferencias contextuales obvias, durante su exilio. Ollier (2005) reconstruye cómo Perón conserva su liderazgo bajo estas circunstancias al lograr una doble colocación: estar y no estar en la escena nacional. Su ausencia física no impide la influencia de su palabra y de su presencia (frente a los visitantes en su exilio). Esto lo lleva a tener múltiples voces y emisarios (los mediadores) que explican el fracaso de jugar exitosamente contra su voluntad y lograr un peronismo sin Perón. En este contexto, el caudillo ve la oportunidad representada por los estallidos de violencia social iniciados en 1968 contra el régimen autoritario que junto a la emergencia de la guerrilla revitalizan su lugar en la escena política. Liderando las diversas facciones contenidas en el interior del movimiento en una operación de acuerdo y confrontación con las otras fuerzas políticas, con los militares y con el gobierno, pero en el marco general del consenso, Perón se convierte en el líder clave que coaliciona la oposición social y política al régimen militar hacia una transición ${ }^{8}$.

\section{LIDERAZGO CARISMÁTICO DE SITUACIÓN: CARLOS MENEM Y NÉSTOR KIRCHNER}

Esta sección analiza la competencia "horizontal" entre aspirantes al máximo liderazgo temporal, atendiendo a las normas formales e informales que enmarcan la etapa post-1983. El liderazgo peronista sigue la tradición fundada por Perón y en consecuencia imbrica jefatura presidencial y partidaria, apelando a la legitimidad de las urnas como corolario de la misma. En la primera etapa (1983-1999), a la renovación política que implica la búsqueda de un líder, continúa la consagración de una nueva jefatura encarnada en Carlos Menem. La etapa siguiente se inicia con la ausencia de un liderazgo nacional, al terminar aquél su mandato, hasta la entronización de Néstor Kirchner.

Vencido en elecciones limpias por primera vez en su historia, en 1983, el justicialismo quiebra la "ley de hierro" de la lógica electoral argentina. Asociada a métodos y personajes del viejo peronismo, la derrota impulsa la renovación. La habilidad desplegada por el justicialismo para sobrevivir unido (al exilio y muerte de Perón) hace que el equilibrio de fuerzas internas marque sus objetivos y sus rumbos. Después de 1983, este equilibro vuelve a definir sus

8 Para más detalles de este proceso, Ollier (2005). 
pasos hasta llegar a la renovación, que presencia el desplazamiento del sindicalismo de la cúpula del movimiento (Gutiérrez, 2000; Levitsky, 2003), mientras otro actor gana espacio en la conducción peronista, los gobernadores (Levitsky, 2003).

Sin embargo, Perón imprime al justicialismo con una marca imborrable: el jefe del movimiento es indiscutido. Reúne en sus manos el poder necesario para ejercer la conducción que radica en la subordinación, por convicción, de sus seguidores. La interpretación de Halperín Donghi (2004) acerca de la nula importancia que Perón atribuyó al destino de su movimiento al colocar, en 1973, a su mujer Isabelita como vicepresidenta, y por lo tanto sucesora, se puede acompañar por concepción del liderazgo, sostenida por el anciano caudillo, y enunciada en su discurso de despedida al pueblo argentino. Me llevo en mis oídos la más maravillosa música que es la voz del pueblo argentino son palabras que encierran el último apotegma que el anciano caudillo transmite a sus discípulos.

Aquella frase contiene, en lo más hondo de su pensamiento, su verdadera concepción de la conducción y en consecuencia de la política. La lección que Perón deja a los justicialistas es sencilla. La jefatura no se delega ni se hereda; se conquista en la lucha política. Por lo tanto, su heredero dentro del movimiento sería aquel dirigente capaz de atravesar exitosamente esa experiencia. Con esta lección a cuestas, el justicialismo jaqueado por la derrota de 1983 se dispone a buscar un nuevo conductor. Ese camino encuentra su punto de llegada el 9 de julio de 1988 cuando Carlos Menem bate a Antonio Cafiero en la competencia interna partidaria por la candidatura presidencial.

Esta regla de selección del candidato es el fruto de la renovación que comienza cuando Ítalo Luder, postulante presidencial elegido por el congreso partidario, sufre un serio revés en las elecciones de 1983 (aunque el peronismo triunfa en 12 gobernaciones, obtiene numerosos diputados y la mayoría de senadores). Emerge entonces la fuente de poder federal capaz de disputar la jefatura del movimiento al sindicalismo nucleado en las 62 Organizaciones (Levitsky, 2003: 109). De Ipola (1987) y Arias (2004) critican la falta de mudanza ideológica y política y advierten que la renovación sólo logra el surgimiento de un nuevo líder. Este logro, sin embargo, no debe subestimarse, pues como lo advierte el propio De Ipola (1987: 350): “En el peronismo (también en la Renovación) la nostalgia de la garantía absoluta de verdad y eficacia que proporcionaría un liderazgo fuerte y carismático -capaz pues de investir la figura del poder- aún no se ha disipado. No por casualidad muchas de las más relevantes propuestas del peronismo renovador buscan autolegitimarse apelando al aval ex ante de la palabra de Perón". Que la legitimidad de la nueva jefatura haya sido el voto ciudadano permite que el resultado de las disputas intrapartidarias quede sujeto a esa legitimidad: la soberanía popular expresada en el sufragio.

Carlos Menem imbrica liderazgo presidencial y partidario, ejerciendo su mandato a partir de concentrar poder en sus manos. Para ello encuentra su legitimación, por un lado, en las vertientes políticas que lo acompañan en la competencia partidaria y, por otro, en la base social que lo respalda posibilitándole representar ambos extremos del arco social: el establishment y las clases populares. Menem resume en su figura el peronismo de las 
clases populares y el antiperonismo de las clases altas, sobre todo en su diseño económico y estatal. Junta así los confines de la pirámide socioeconómica, del mismo modo que Perón había unido pueblo y Fuerzas Armadas.

Similar a Perón, advirtió Arias (2002), Menem se autodefine un conductor. La tradición peronista fundada en la confianza en el líder como conductor de la refundación de la Nación y de la unidad del pueblo, las invocaciones contra la clase política, su presentación como un outsider y el pragmatismo político le facilitan tanto la gobernabilidad como el ejercicio personalizado del poder. En ese marco subordina el sindicalismo y el partido a su voluntad ${ }^{9}$, y el justicialismo vuelve, al igual que bajo Perón, a funcionar referenciado en su conductor. De ahí que el cambio de ideas económicas no es sólo responsabilidad de Menem: el Congreso de Actualización Doctrinaria, en 1991, logra que el partido acepte el nuevo modelo (Palermo y Novaro, 1996: 28) ${ }^{10}$. La convicción sobre la eficiencia tecnocrática conquista el discurso político.

Con una opinión pública aliada a sus propuestas de reforma, Menem completa la construcción de su liderazgo e impone sus políticas. Conduce con mano férrea el Poder Legislativo (contando con mayoría en el Senado y por períodos en Diputados) ${ }^{11}$ y nombra nuevos magistrados en la Corte Suprema, que acatan su voluntad al punto que popularmente se la denomina "mayoría automática". Menem corona su liderazgo con transformaciones discursivas en relación al peronismo tradicional, dejando atrás las viejas banderas de imperialismo o nación. En este escenario prosigue el debilitamiento del actor militar iniciado con Alfonsín ${ }^{12}$.

O'Donnell (1995) define la democracia argentina bajo Menem como delegativa y, desde mi lectura, la centralidad de su liderazgo en un contexto de baja institucionalización resulta crucial en su definición. Esa preponderancia de su jefatura encuentra el límite temporal impuesto por el calendario electoral. Así cuando Menem fuerza una interpretación de la Constitución para lograr su habilitación por un tercer período, la resistencia más efectiva proviene del propio justicialismo y la encabeza Eduardo Duhalde, el candidato más firme a sucederlo en la presidencia. De ahí que al terminar su segundo mandato se debilitan sus chances de continuar siendo el líder máximo del peronismo. Consagrada la regla de elecciones internas para elegir candidato a presidente, el PJ establece el 4 de julio de 1999 como fecha de los comicios. Al bajarse de la precandidatura Adolfo R. Saá, previo a la reunión de gobernadores peronistas que le reclamaría ese gesto, despeja el camino a

\footnotetext{
9 Importantes sindicatos cooperaron con su gobierno (Murillo, 2000, 2001). Los nexos con el gremialismo fueron cruciales al permitirle conservar su poder en todos los organismos oficiales, colaborando en sus gestiones al frente del Estado nacional (Levitsky, 2003: 224).

10 Sidicaro (2002) señala los beneficios materiales y simbólicos provenientes de la obtención de cargos públicos. Levitsky (2003) demuestra cómo se organiza una red clientelar basada en los recursos del Estado que vino a reemplazar los viejos lazos partidarios.

11 Sobre el uso abusivo de los decretos de necesidad y urgencia, Mustapic (2000).

12 Menem redujo a un tercio a las Fuerzas Armadas, recortó su presupuesto y lo puso bajo la supervisión del ministro de Economía, privatizó empresas militares y terminó con el servicio militar obligatorio.
} 
Duhalde como postulante del PJ (Clarín, 8/6/1999). Su derrota en la elección presidencial pone al peronismo, nuevamente, frente a la ausencia de un líder nacional.

La nueva columna vertebral conformada por los gobernadores pasa a dirimir los acuerdos y las divergencias en su seno. La resolución de los conflictos va a depender del equilibrio de poder (esta vez entre los barones provinciales) tal como había sucedido en los períodos 1955-1973 y 1974-1988. La derrota del peronismo lleva al gobierno a una Alianza entre dos fuerzas políticas. La salida anticipada de su presidente Fernando de la Rúa, como resultado de la crisis de 2001, conduce a la Asamblea Legislativa a nominar a Eduardo Duhalde Presidente provisional de la República.

Este período (1999-2003) de disputa abierta por la nueva jefatura no siempre ha sido comprendido. Levitsky (2003) estudia el menemismo y luego traza la trayectoria posterior del peronismo, entre 1999 y 2003 (Levitsky, 2005), denominándolas de renovación y de caos respectivamente. En su perspectiva, la fragilidad institucional permite al PJ tanto adaptarse eficazmente a los cambios como caer en el caos $^{13}$. Sin embargo, mientras en las etapas de caos el peronismo carece de un líder máximo (1983-1989 y 1999-2003), por el contrario, la renovación comprende aquel período donde el PJ exhibe un único jefe (1989-1999). El error de interpretación radica en ubicar a la debilidad institucional, que facilita la capacidad de adaptación, como variable independiente sin dar mayor relevancia a la relación entre fortaleza organizativa y liderazgo; vínculo explicativo clave de la diferencia entre ambas situaciones del PJ.

Entre 1999 y 2003, ante la ausencia de un jefe indiscutido, Duhalde en un acuerdo con los gobernadores peronistas y con la bancada radical en el Congreso resuelve que "por única vez" cada partido elija sus candidatos presidenciales con el método que prefiriese. El peronismo presenta tres candidatos, dos de los cuales alcanzan el ballotaje. La deserción de Menem en la segunda vuelta ubica a Néstor Kirchner en la presidencia.

Al reconstruir cómo Kirchner organiza su liderazgo presidencial y partidario, Ollier (2005) plantea que Kirchner lidera el re-armado del modelo económico implementado por su antecesor desde una posición desventajosa dado su bajo caudal electoral $(22 \%)$ y la sombra de su mentor, Duhalde, merced a cuya máquina electoral alcanza la presidencia. Sin embargo, opta por cimentar su liderazgo presidencial en la concentración personal de poder. Se convierte entonces en el nuevo jefe partidario del PJ (primero informal y después formal). Al igual que Menem, Kirchner 1) prioriza el tiempo político apelando al favor de la opinión pública (Cheresky, 2004), diferenciándose de la desprestigiada "corporación política", contra la cual vociferaba la clase media al son del "que se vayan todos" en 2001; 2) busca aliados fuera del PJ, pero a diferencia de Menem los encuentra en el otro extremo del espectro ideológico con un sesgo de centro-izquierda, y 3) renueva la Corte Suprema,

13 Levitsky (2005: 184) define al peronismo como "a distinctive combination of organizational strength and institutional weakness". 
bajo la excusa de terminar con el desprestigiado organismo "menemista", con jueces que resultan figuras prestigiosas del ámbito judicial.

La aprobación ciudadana le permite gobernar con gran margen de poder personal, por lo cual aprovecha las elecciones legislativas de 2003 y de 2005 para incorporar diputados afines y carecer de obstáculos en el Congreso, que por otra parte casi no funciona durante su mandato. La influencia sobre el actor sindical, propio de un presidente peronista, completa la centralización del poder. Cumplido su mandato, y ubicada su esposa como sucesora, Kirchner asume la jefatura del PJ que había estado vacante esos años.

La organización peronista reciclada. Luego de 1983 el peronismo transita hacia un liderazgo temporal, carismático de situación (Panebianco, 1990), sin perder el rasgo de concentración de poder personal ${ }^{14}$. Según Tucker (1970: 81-82), este carisma se constituye más por un estado de predisposición de la comunidad que por características mesiánicas del líder, quien ofrece una salida a la situación de malestar por la que atraviesa la colectividad. El surgimiento del carisma de situación responde a "un estado de stress agudo en la sociedad que inclina a sus miembros 'a percibir como extraordinariamente cualificado y a seguir con lealtad entusiástica un liderazgo que ofrece una vía de salvación de la situación de stress'". Tanto Menem como Kirchner llegan al gobierno luego de severas crisis económicas. Aun cuando el segundo toma el gobierno con la solución a la crisis encaminada, en el ánimo colectivo todavía impacta la hecatombe del 2001.

El carisma de situación se diferencia del puro (Panebianco, 1990: 114) por una inferior capacidad del líder para plasmar a su gusto las características de la organización, y pese a su enorme poder, el partido no resulta su criatura sino que brota de una pluralidad de impulsos. Por lo tanto, otros actores se reservan grados de control sobre las zonas de incertidumbre de la organización. En los momentos sucesorios, cuando las exigencias electorales requieren un nuevo presidente y en consecuencia otro jefe peronista, es cuando la presencia de otros actores se hace sentir. Dado que desde 1983 el PJ no respeta una única regla de selección de sus candidatos (Mustapic, 2002), este artículo argumenta cómo irrumpen los liderazgos carismáticos de situación que continúan estructurando la organización peronista.

La muerte de Perón y la consolidación democrática acaban con el carácter "eterno" de la jefatura peronista y su reemplazo por otro de naturaleza "temporal", ajustado a las necesidades electorales que impone la democracia. En consecuencia, la imbricación del liderazgo presidencial y partidario, acotada por los tiempos electorales, refuerza el carácter competitivo del peronismo en la arena electoral. Por lo tanto, el PJ recurre en las más diversas circunstancias a un mecanismo último de legitimidad del liderazgo: el sufragio.

En cuanto a la organización política, siguiendo a Panebianco (1990), el peronismo fusiona trazos de tres modelos: 1) carismático que implica ausencia de institucionalización y una fortísima centralización de la autoridad, 2) de masas, signado por su marcada

14 Panebianco (1990: 113) extrae el concepto de Tucker (1970). 
desideologización (Panebianco, 1990: 490) que le confiere el atributo pragmático que el mismo Perón le imprimió ${ }^{15}$ y 3 ) de gobierno, es decir, el justicialismo lleva a cabo su proceso de organización desde el centro, o sea, desde el gobierno -en este caso inclusive desde el Estado- y no desde la periferia. Este último modelo, concluye el autor, acarrea una institucionalidad débil, pues los líderes están desinteresados en lograr una institución fuerte en tanto los incentivos selectivos se encuentran en el Estado. Por lo tanto la débil institucionalización se debe a sus rasgos de partido carismático y de gobierno, mientras la desideologización es atribuible al hecho de ser un partido de masas.

La combinación peronista original se mantiene hasta 2007 reciclada bajo los liderazgos carismáticos de situación o temporales: baja institucionalización, centralización de la autoridad, marcada desideologización, pragmatismo y orientación hacia el gobierno y el Estado. Con el retorno de la democracia, el límite temporal a la jefatura del movimiento es impuesto por la duración del mandato presidencial. Sin embargo, luego de 1983 la organización peronista adquiere un rasgo del partido electoral-profesional (Panebianco, 1990: 490). Cavarozzi (2006) refiere a la profesionalización de la política que alcanza al PJ. El partido de profesionales maximiza el voto para obtener cargos públicos, sin debates de ideas o de programas, ni discusión sobre mejores formas de organización. El presidente decide la agenda. En ese contexto, la organización peronista manejando al Estado en todos los niveles donde gobierna (nacional, provincial y local) acompaña (con menor o mayor euforia) el decisionismo del Ejecutivo ${ }^{16}$.

Se da entonces un exitoso entrelazamiento: la victoria electoral legitima la jefatura y garantiza el acceso al Estado; este último, a su vez, proporciona los recursos. Si bien los vínculos de clientela y patronazgo imperan en todos los partidos, la diferencia radica en el grado de institucionalización de las fuerzas políticas: cuando ésta es mayor, la institución opera esas conexiones, en cambio, cuando es menor, dichos enlaces los guía un boss individual (Panebianco, 1990: 130). El PJ despliega numerosas unidades básicas que se ocupan de estos nexos (Levitsky, 2003).

La sección expuso las diferentes circunstancias que guiaron la competencia horizontal, pues la ausencia de un jefe eterno conlleva una disputa entre los aspirantes a ese lugar. En 1983 el Congreso partidario, donde el peso sindical resulta mayor, nomina a Luder candidato a la presidencia. La renovación establece luego las elecciones internas para llevar a cabo esa nominación. Esta regla se cumple en 1988 y el triunfo de Menem significa la emergencia de un nuevo líder. Frente a su sucesión, la práctica se cambia, por lo cual Duhalde es proclamado aspirante justicialista. Pasada su presidencia provisional, con la caída de De la Rúa, en 2003 el PJ propone, sin su sigla, tres candidatos peronistas a la presidencia, sometiendo la elección de su postulante a una competencia abierta obligatoria. Es decir, fuera de la selección que corona a Menem, el PJ jamás vuelve a ejercitar, al menos hasta

15 Sobre la desideologización del peronismo, Buchrucker (1986).

16 Término acuñado por Quiroga (2005). 
el 2007, su regla de comicios internos para la nominación del aspirante. Tampoco en esta ocasión se practica la norma formal. Sin embargo, el reconocimiento de una única regla informal como legitimación última del líder, el voto ciudadano, consagra frente al uso cambiante de los instrumentos sucesorios a Menem y al matrimonio Kirchner, e impide el arribo de otros (Duhalde, Rodríguez Saá, Menem en 2003). Luego de 1983, por debajo de la disputa horizontal, y tomando parte en ella, se despliegan las relaciones verticales que alinean los liderazgos provinciales y locales.

\section{EL LIDERAZGO PERONISTA EN EL CONURBANO BONAERENSE (1983-2007)}

La presencia de un líder temporal indiscutido no impide disputas entre los jefes locales para alcanzar el máximo lugar en su distrito. Como resultado de esas confrontaciones, el peronismo local se reorganiza en torno al vencedor. Por lo tanto, esta sección analiza el alineamiento, entre 1983 y 2007, de las jefaturas peronistas locales del Conurbano Bonaerense (de ahora en más CB) con el liderazgo máximo para corroborar, en un caso empírico, la hipótesis que sustenta el artículo: el liderazgo político estructura al peronismo como organización política, siendo el voto ciudadano la legitimación última de ese liderazgo, legitimación que debe darse en las tres jurisdicciones ${ }^{17}$. Primero presento el $C B$, luego bosquejo el diseño institucional local y finalmente despliego los alineamientos comunales con los liderazgos peronistas provinciales y nacionales entre 1983 y $2007^{18}$.

El CB es el anillo de la provincia de Buenos Aires, con 35\% de la población argentina, que rodea a la ciudad autónoma de Buenos Aires ${ }^{19}$. El CB comprende el 62,81\% de los habitantes provinciales, siendo el área con más votantes del país (Cormick, 1997), extendiéndose en parte de la primera y tercera sección electoral (SE) de las ocho que forman la provincia. Diez municipios, antes de 1995, y catorce posteriormente (Morón, Hurlingham, Ituzaingó -las tres eran Morón-, José C. Paz, Malvinas Argentinas, San Miguel -las tres eran General Sarmiento-, San Martín, Merlo, Moreno, San Fernando, San Isidro, Tigre, Tres de Febrero y Vicente López) integran la primera SE del CB. La tercera SE del CB incluye nueve y luego diez municipios (Almirante Brown, Avellaneda, Berazategui, Esteban Echeverría, Ezeiza, Florencio Varela, La Matanza, Lanús, Lomas de Zamora y Quilmes) ${ }^{20}$.

17 Esta sección es parte de una investigación más amplia sobre la política bonaerense, donde la información ha sido provista por organismos provinciales y locales, periódicos y entrevistas a políticos y periodistas.

18 Los alineamientos locales con el vencedor de la interna partidaria, terminada la competencia, ocurren en todos lados; la diferencia en el peronismo es que son por posicionamientos personales. Ergo, terminada la confrontación, el alineamiento con el vencedor esfuma la disputa.

19 Los estudios sobre el CB comenzaron en las últimas décadas: la democracia local (Amaral y Stockes, 2005), los partidos políticos (Anunzziata, 2006; Roca Rivarola, 2006), la gestión municipal (Cormick, 1997), el diseño institucional (Bennardis, 1999; Passalaqua, 2001; Recalde, 2009), el gobierno local (Badía, 2001; Gormick, 1997/2001), el Fondo de Reparación Histórica (Chiara, Danani y Clic, 1997), las relaciones entre género y poder (Masson, 2004), los sectores populares desde distintas problemáticas: el clientelismo (Auyero, 1997), la moral (Frederic, 2004), las formas de supervivencia (Hintze, 1989), la desocupación (Iñiguez y Sánchez, 1995) y los saqueos a comercios durante la crisis de 2001 (Auyero, 2007).

20 El CB es sinónimo de lo que el INDEC denomina Partidos del Gran Buenos Aires, www.indec.mecon.gov.ar 
Bajo el formato federal, la Argentina encierra un rasgo unitario de gobierno que nace en presidentes con enorme poder institucional y financiero en relación a los gobernadores, y termina en la misma concentración de poder de los gobernadores sobre los intendentes. En Buenos Aires, la centralidad del ejecutivo municipal, facilitada por el diseño institucional, completa el cuadro (Cravacuore, 2001: 5). La concentración de decisiones en el jefe comunal promueve una dinámica política en torno al intendente, donde cualquier nimiedad requiere su firma. Al centralismo se suma otra regla que acrecienta su poder: la reelección indefinida ${ }^{21}$. Los intendentes peronistas utilizan su poder para alinearse con un liderazgo incuestionable o para tomar parte de la disputa entre jefes de la jurisdicción superior. El poder de estos jefes comunales encuentra su fin cuando triunfa un partido adversario (lo cual es infrecuente) o cuando el liderazgo peronista provincial o nacional decide confrontarlo apoyando un rival local.

Los contrapesos locales resultan escasos, pues el Concejo Deliberante (CD), organismo con la facultad de destituir por ley al intendente, no es tal por tres razones. La primera yace en la sucesión. Radicada ésta en el primer concejal de la lista del partido del intendente, la destitución suele responder a disputas facciosas dentro del oficialismo o a una alianza de una facción peronista con la oposición. La segunda razón reside en el diseño de la boleta electoral, que subordina el Legislativo al Ejecutivo en tanto las candidaturas, a ejecutivo local y a concejales, se encuentran en el mismo cuerpo de la boleta electoral. En consecuencia votar a tal intendente implica votar por "sus" concejales ${ }^{22}$. La tercera razón radica en el sistema de cociente para la asignación de los concejales. Este método favorece al intendente al engrosar las filas de sus concejales en el CD. Los partidos más votados poseen mayor representación de manera desproporcional, pues el sistema fortalece al partido del intendente, luego a una sola fuerza de oposición y finalmente desalienta las agrupaciones nuevas. Entonces, centralidad del Ejecutivo, concentración de decisiones en el jefe comunal, reelección indefinida, diseño de la boleta electoral y sistema de cociente en la distribución de los concejales otorgan al intendente un alto poder de decisión para garantizar obediencia dentro del peronismo.

Veamos cómo se despliegan las diferentes jefaturas peronistas locales entre 1983 y 2007, a partir de reconstruir las disputas horizontales a nivel nacional y/o provincial y la relación vertical entre los líderes máximos y las jefaturas provinciales y/o locales. En 1983, Herminio Iglesias encarna al jefe justicialista bonaerense. Acusado de espantar los votos de la clase media por quemar un féretro en el cierre de campaña y culpado de la derrota, Iglesias pertenece a la rama sindical. Su fracaso en acceder a la gobernación de Buenos Aires frente al contrincante radical lo debilita dentro del peronismo, que no acepta jefes derrotados en las urnas. Antes que una máquina electoral, el herminismo constituye una corriente de los caudillos peronistas clásicos

21 Recalde (2009) rastrea todos los diseños municipales de Buenos Aires desde la colonia.

22 A este diseño se suman disposiciones como el artículo 119 de la ley orgánica municipal que autoriza a los concejales a facultar en forma general a los jefes comunales para transferir créditos y crear o modificar partidas que éstos usan para concentrar atribuciones y gobernar sin rendir cuentas. Todos los intendentes pueden cambiar, sin control alguno, partidas de libre disponibilidad (La Nación, 27/01/2008). 
junto a sindicatos importantes nucleados en las 62 Organizaciones (agrupamiento sindical peronista) y en la Unión Obrera Metalúrgica (UOM) (poderoso sindicato comandado por el peronismo). Excepto el Sindicato de Mecánicos y Afines del Transporte Automotor (SMATA), conducido por José Rodríguez, el herminismo representa al resto del espectro gremial. Ahora bien, sobre los 19 distritos del CB en 1983, el PJ gana 10 de ellos. De estos diez jefes locales, siete se referencian en Iglesias ${ }^{23}$, mientras sólo tres mantienen cierta autonomía, aunque comparten la boleta electoral con Iglesias gobernador ${ }^{24}$.

Derrotado el peronismo a nivel nacional y provincial, comienza la renovación encabezada por el bonaerense Antonio Cafiero. Éste disputa el liderazgo de Iglesias en las elecciones legislativas de 1985. Llevando adelante una táctica que luego se popularizaría en el PJ, esto es, ganar elecciones por fuera del partido para lograr más poder adentro, Cafiero compite en la provincia triunfando -al conseguir el segundo lugar- sobre Iglesias, quien sale tercero. La legitimidad de las urnas deja a Cafiero como jefe del PJ y candidato a gobernador por Buenos Aires. En 1987, obtiene el cargo y la renovación que él encarna se beneficia en las urnas del CB. El método de elecciones internas para elegir los candidatos a intendentes muestra el nuevo alineamiento del peronismo del conurbano: el cafierismo triunfa en la mayoría de los distritos. En la elección municipal el PJ conquista 15 intendencias cuya mayoría (10) pasa a manos del cafierismo ${ }^{25}$. Un solo candidato menemista vence en ambas competencias ${ }^{26}$. Los cuatro caudillos restantes renuevan compartiendo, igual que aquél, boleta con Cafiero, el nuevo jefe provincial ${ }^{27}$.

El triunfo de Menem en la competencia interna contra Cafiero se convierte en la victoria de la organización peronista centrada en un jefe, como lo fue en vida de Perón. En la competencia horizontal entre ambos por la candidatura presidencial, excepto una ínfima minoría entre quienes están Rousselot y Toledo que sostienen a Menem, la mayoría de los intendentes del CB se alinean verticalmente con su jefe provincial. Su derrota es la prueba más contundente de que Cafiero no había armado una máquina electoral en su provincia.

El riojano vence en las presidenciales de 1989, llevando a Eduardo Duhalde como vicepresidente en recompensa por su labor en territorio bonaerense. Ubicado Menem en el lugar de Presidente de la Nación y líder partidario, la jefatura de Cafiero en Buenos Aires se debilita. Éste convoca un plebiscito para reformar la constitución provincial y ser autorizado para otro período, pero la victoria del NO a la reforma lleva al PJ a apartarlo de la conducción nacional. Duhalde que ni apoya la reforma ni queda identificado con los menemistas ultraortodoxos que vociferan contra ella, transforma los enredos entre menemistas y cafieristas en una ventaja y se alza con la presidencia del PJ bonaerense.

\footnotetext{
J. López, A. Viviant, M. Quindimil, L. Suárez, H. Ibáñez, F. Russo y A. Ramón.

E. Duhalde, J. Carpinetti y F. Flores.

C. Brown en San Martín, G. Green en Merlo, E. Lombardi en Moreno, J. Mangas en Tres de Febrero, H. Toledo en Lomas de Zamora, E. Caamaño en Quilmes, J. Villaverde en Almirante Brown, J.J. Mussi en Berazategui, L. Obarrio en E. Echeverría y J. Carpinetti en Florencio Varela.

26 J.C. Rousselot.

27 Quindimil en Lanús, López en G. Sarmiento, Viviant en San Fernando y Russo en La Matanza.
} 
A pedido de Menem, Duhalde abandona la vicepresidencia de la nación para competir, en 1991, por la gobernación bonaerense, donde el PJ retiene quince (15) intendencias. Su triunfo implica el inicio de su liderazgo provincial. Los intendentes peronistas del CB responden a la dupla Menem-Duhalde, que unidos atraviesan las elecciones presidenciales y a gobernador, en 1995, previa reforma de ambas constituciones que los habilitan para otro período. La fortaleza del binomio Menem-Duhalde en el CB Ileva al PJ a conquistar veintiún distritos en 1995. El Fondo de Reparación Histórica del CB que Duhalde había puesto como condición para ser candidato en 1991 ha dado sus frutos ${ }^{28}$. De allí extrajo los recursos para armar su máquina político-electoral. Para 1995, año del esplendor del binomio, seis intendentes conservan su afinidad menemista ${ }^{29}$, mientras los dieciséis restantes siguen leales a Duhalde.

Sin embargo, poco a poco Duhalde pasa de ser el sucesor de Menem a transformarse en su adversario, cuando el presidente intenta forzar la interpretación de la Constitución reformada en 1994 para postularse a un tercer período. ¿Cómo impacta en el CB esta confrontación? La disputa se inicia visiblemente hacia 1997 y como resultado cinco de los seis intendentes menemistas sufren distintos traspiés en sus distritos y terminan sus mandatos. Libonati, Rousselot y De Luca resultan destituidos por el CD (clara lucha facciosa del peronismo local), Glaría en 1999 es confrontado por una tendencia interna local apoyada por Duhalde y vencido por su candidato Mario Ishii, y Álvarez se pasa al bando duhaldista. Granados deviene el único sobreviviente menemista. Al Ilegar la elección presidencial de 1999, Fernando de la Rúa, un postulante salido de una coalición entre dos partidos, vence a Duhalde.

Como señalé antes, la salida anticipada del Presidente De la Rúa conduce a Duhalde, en 2002, a la presidencia provisional de la República. La disputa entre él y Menem lo lleva a maniobrar para que el PJ presente, con diferentes siglas, en abril de 2003, tres candidatos a presidente, Carlos Menem, Néstor Kirchner y Adolfo Rodríguez Saá. En Buenos Aires las elecciones a presidente y gobernador se desdoblan siendo las segundas unos meses más tarde. Si en las presidenciales de 2003 dos intendentes (Othacehe en Merlo y Granados en Ezeiza) no llevan todos sus votos a Kirchner, las de septiembre a gobernador e intendente ven a los 18 candidatos peronistas alineados con el candidato a gobernador, Felipe Solá, es decir con Duhalde y Kirchner. Éste comienza el camino para convertirse en el nuevo jefe (informal) justicialista, aunque ensombrecido por el poder de Duhalde en Buenos Aires.

Las elecciones legislativas de 2005 ofrecen a Kirchner la ocasión para asestarle un duro golpe a Duhalde y quedar como jefe indiscutido del PJ. Así el peronismo, bajo diferentes siglas, Ileva dos listas; una propuesta por Kirchner encabezada por su mujer, Cristina, como candidata a senadora nacional por Buenos Aires; la otra lista la organiza Duhalde siendo la postulante al mismo cargo su esposa, Hilda (Chiche) de Duhalde. Ambas dividen el apoyo

28 Se trata de un subsidio de 2 millones de dólares diarios, compensatorio por la inmigración del interior del país hacia Buenos Aires, que el gobernador utilizó discrecionalmente. Ver Chiara, Danani y Flic (1997).

29 J.C. Rousselot, A. Granados, R. Glaría, J.J. Álvarez, J. De Luca y en el límite A. Libonati. 
de los intendentes peronistas. Mientras Duhalde cuenta a diez a su favor ${ }^{30}$, Kirchner suma siete $^{31}$. El Presidente apela a una táctica conocida: ganar una elección general por fuera del PJ para disciplinar adentro.

Los discursos de las dos candidatas prueban hasta qué punto se trata de una contienda intraperonista. Del lado del Frente para la Victoria, el partido electoral de Kirchner, la candidata se ve favorecida por la participación del Presidente de la Nación y de miembros de su gabinete. El lanzamiento de su postulación devela la nacionalización de los comicios propuesta por Kirchner al reunir trece gobernadores, varios legisladores, funcionarios e intendentes del conurbano. La elección pone en juego el proceso nacional: "Se trata de la Argentina". La necesidad de los votos de la clase media para triunfar queda reflejada en la estética de los actos, en general despojados de la liturgia peronista, mientras que la atracción de sufragios justicialistas se traduce en la confrontación con el peronismo bonaerense. Desde esa perspectiva, Cristina confiesa estar "harta" de que se acuerden de Perón y Evita sólo en los discursos (Clarín, 17/7/05). La Figura de la abanderada de los humildes emerge como eje de la disputa femenina por el voto y la interpretación del peronismo, siendo convertida, en el discurso oficialista, en Madre de Plaza de Mayo (Clarín, 27/7/05; Clarín, 28/7/05).

Cristina Kirchner sostiene que la elección no pone en juego el control sino la gobernabilidad y las transformaciones acaecidas (Clarín, 27/7/05). La injerencia presidencial sigue siempre un mismo patrón: el anuncio de obras públicas en cada distrito. Kirchner vuelca el peso de su lugar privilegiado en las encuestas, la popularidad de su gobierno, el poder de movilización peronista y los recursos del Estado nacional. Un discurso de tinte fundacional establece la primera ruptura con el pasado inmediato simbolizado en Duhalde, pues Kirchner precisa suprimir que le debe su arribo a la presidencia y que el justicialismo bonaerense, comandado por Duhalde, lo apoyó en su gestión (por ejemplo, en el Congreso aprobando las leyes que el FMI requería para continuar las negociaciones). Afilada en la escalada verbal y para borrar las deudas con el pasado, Cristina remata: "Cuando interponen escollos institucionales para que se gestione, eso no es libreto peronista: es guión y dirección de Francis Ford Cóppola; y no es manual de conducción política: es la película "El Padrino".

Los ataques acusan a Duhalde por ineficiencia, al dejar caer la provincia y despilfarrar el Fondo de Reparación. Cuando Hilda Duhalde imputa a Cristina Kirchner de desconocer la provincia, Kirchner responde: "Si conocen la provincia ¿por qué la dejaron caer tanto?" (Clarín, 15/7/05) "No sólo a la provincia de Buenos Aires la alquilaron y vendieron sino al país todo. Destrozaron económicamente a este país (...)". Remata acusando a Duhalde de aliado de Menem, agraviando la década del 90, que él mismo apoyó: "El gobierno de la provincia tendría que haber hecho lo que me tocó hacer a mí en Santa Cruz y pararse ante ese presidente que entregaba la Argentina cotidianamente y ahora está escondido en La Rioja" (Clarín, 28/7/05).

30 H. Curto, J. Cariglino, F. Amieiro, L. Acuña y O. Zilocchi, B. Álvarez de Olivera, J. Rossi, J. J. Mussi, M. Quindimil y M. Rodríguez.

31 A. Descalzo, R. Othacehé, A. Arregui, M. Ishii, J. Pereyra, A. Ballestrini y A. Granados. 
El discurso oficial anuncia tiempos fundacionales, la genuina vocación de poder, el valor de la institucionalidad, el aprovechamiento de la oportunidad abierta. Ellos son los que no se dejan intimidar (ni por los adversarios de adentro ni por los organismos internacionales de crédito), los que hablan con la verdad y cumplen las promesas. Los Kirchner se erigen en los verdaderos ejecutores de la política de Perón y de Eva. Del otro lado se encuentra el viejo peronismo y los restos de aquello que alguna vez fue. Este adversario, falso peronista, mentiroso y timorato, construye poder incorrectamente, no cumple las promesas, Ilevando al país a un desastre sin confrontar con el neoliberalismo.

A la inversa, el duhaldismo provincializa la elección. Chiche Duhalde no injuria a su adversaria, a quien incrimina por no pertenecer al PJ sino a otro partido y por desconocer Buenos Aires al provenir de Santa Cruz (Clarín, 14/7/05). Erigida en legítima representante del peronismo bonaerense, adelanta que sus disputas en el Senado reclamarán recursos para aumentar la coparticipación de Buenos Aires (Clarín, 12/7/05). Reiteradamente y a diferencia de su contrincante, Chiche alude a su "orgullo" de ser peronista y bonaerense. Inculpa a Kirchner de haberla presionado para que no sea candidata (Clarín, 12/7/05). Un diputado duhaldista le recuerda a Kirchner su deuda al afirmar: "Hace dos años que con este Presidente yo manejo la Cámara y saqué todas las leyes pedidas". "No entendemos por qué razón ocurrió esta situación, que está llevando a un enfrentamiento innecesario" (Clarín, 29/7/05). E. Caamaño, diputado nacional, le recuerda al presidente su origen: "Yo creí que el kirchnerismo era parte de lo nuestro, porque así habíamos Ilegado", pero descubre que la política del Presidente es "la destrucción del PJ y yo no voy a permitir eso" (Clarín, 22/7/05).

Ante un auditorio Ilamando "traidores" a los otrora dirigentes duhaldistas devenidos kirchneristas, Hilda Duhalde señala: "Cómo agraviarlos (...) si dos de ellos fueron secretarios privados de mi marido (...) si, una semana antes, visitaron mi casa" (La Nación, 10/7/05). A diferencia del discurso oficial que pretende cortar con el pasado, ella rememora que el peronismo bonaerense ayudó mucho para que Kirchner llegara a la presidencia. En ese marco defiende a su marido (Clarín, 14/7/05), explicando que el Presidente se disgustó con él porque defendía al peronismo (Clarín, 14/7/05). Su discurso también advierte sobre dos campos, uno ocupado por el buen padre peronista y el otro por sus hijos ingratos, que reniegan del peronismo y quieren destruirlo. Regresa, entonces, un viejo debate de la tradición peronista: quién y cuál es el verdadero peronista, el único intérprete de esa peronicidad. La disputa central queda instalada en la definición de la identidad peronista: el FpV la construye acorde con los nuevos tiempos mientras el duhaldismo cuida la tradición.

El impacto de la intervención presidencial y la inclusión de la clase media como destinataria de buena parte de la campaña llevan a Cristina Kirchner a la victoria en municipios (San Miguel, Malvinas Argentinas, Tres de Febrero, San Fernando y Hurlingham) cuyos intendentes apoyaron a la esposa de Duhalde (Clarín, 24/10/2005; El Día, 24/10/2003). La derrota de Chiche significa el final de la jefatura de su marido, mientras el triunfo de Cristina ubica a Kirchner como el líder justicialista. Sin rivales de peso, Kirchner se convierte en el jefe indiscutido del CB. Así, aquellos intendentes citados alineados con Duhalde que pierden la elección a concejales pasan rápidamente, luego de la derrota, a las filas kirchneristas. 
Por lo tanto, al llegar las elecciones de 2007, el Presidente impone a su mujer y el tándem Cristina Kirchner a la presidencia y Daniel Scioli a la gobernación de Buenos Aires consigue el efecto esperado en el CB, por la cantidad de votos de sus intendentes ${ }^{32}$. Carecemos de investigaciones para saber si la ciudadanía vota guiada por la figura presidencial o por la local, pues en principio la masa de votantes no es homogénea. De todos modos, miremos los casos de 2007 para tener más elementos de análisis. En principio, la competencia dentro del peronismo ha expuesto la facciosidad que reina en las cúpulas locales del CB, alimentada por el propio Kirchner. El ex Presidente alienta la división premiando a los leales a él y por lo tanto impidiendo en esos casos las listas colectoras y castigando a los menos leales plantándoles una alternativa en el distrito. Así el Presidente en persona diseña la estrategia de sumar votos con varios candidatos propios para las mismas intendencias, concejales y consejeros escolares, lo cual desata una guerra por portar el sello oficialista en Buenos Aires (Clarín.com, 20/09/2007).

Un paso importante consiste en avanzar sobre el PJ provincial. Varios nombres del radicalismo y del socialismo, aliados al kirchnerismo, ocupan lugares que podrían haber sido para el sindicalismo nucleado en torno al dirigente Hugo Moyano (Clarín.com, 14/09/2007). La Junta Electoral provincial pone un límite a esta confrontación interna al declarar que la cantidad de listas presentadas constituye una "ley de lemas encubierta" ${ }^{33}$. Sin embargo, este sistema de listas oficial y "colectora" permite sumar votos a la fórmula que sostiene todas ellas, Cristina Kirchner y Daniel Scioli. Se podía votar por diferentes candidatos a intendentes justicialistas pero la misma boleta a presidente y gobernador. En el CB, esta estrategia pergeñada por el kirchnerismo se resume en el cuadro siguiente, que muestra la disputa entre los jefes locales en su alineamiento con Kirchner.

\section{CUADRO 1}

Listas peronistas locales en el CB en 2007

\begin{tabular}{|l|c|}
\hline \multicolumn{1}{|c|}{ MUNICIPIOS } & LISTAS \\
\hline Lomas de Zamora (1) & 5 \\
\hline San Fernando y Vicente López (2) & 4 \\
\hline San Martín, Hurlingham, San Miguel, Berazategui, Esteban Echeverría, Ezeiza, Quilmes (7) & 3 \\
\hline Malvinas Argentinas, Morón, San Isidro, Tres de Febrero, Avellaneda, Lanús (6) & 2 \\
\hline Ituzaingó, José C. Paz, Merlo, Moreno, Tigre, Florencio Varela, La Matanza (7) & 1 \\
\hline
\end{tabular}

Fuente: elaboración propia en base a El Día, 11/09/2007.

32 En Almirante Brown (65\%), en Avellaneda (56\%), en Berazategui (72\%), en Florencio Varela (64\%), en La Matanza (50,9\%), en Lomas de Zamora (58\%), en Tres de Febrero (50\%), en Quilmes (46\%) (El Día, 29/10/2007).

33 Hay anotadas 134 listas del Frente para la Victoria (www.clarín.com.ar, 20/09/2007). 
Algunos cambios del escenario postelectoral favorecen a la Presidenta dentro del justicialismo. Primero, 23 sobre 24 intendentes ganan compartiendo su boleta. Segundo, en Quilmes, Lanús, Almirante Brown y Esteban Echeverría obtienen la municipalidad candidatos más cercanos al kirchnerismo que los intendentes derrotados ${ }^{34}$.

En suma, la sección evidencia cómo en torno a ciertas elecciones claves se advierten las relaciones verticales que se configuran a raíz de las disputas horizontales por el liderazgo máximo como se resumen en el Cuadro 2.

\section{CUADRO 2}

Combinación de disputas y acuerdos horizontales (o entre nación y provincia) y su impacto en relaciones verticales en el CB

\begin{tabular}{|c|c|c|}
\hline \multicolumn{2}{|r|}{$\begin{array}{l}\text { LIDERAZGOS NACIONAL/PROVINCIAL } \\
\text { RELACIÓN HORIZONTAL EN EL PJ }\end{array}$} & $\begin{array}{l}\text { IMPACTO EN EL CONURBANO } \\
\text { RELACIÓN VERTICAL EN EL PJ }\end{array}$ \\
\hline \multirow{4}{*}{$\begin{array}{l}\text { Disputa } \\
\text { Formal }\end{array}$} & $\begin{array}{l}\text { H. Iglesias vs. A. Cafiero (elecciones legislativas, 1985) } \\
\text { Cafiero gobernador (elecciones, 1987) }\end{array}$ & $\begin{array}{l}\text { De } 10 \text { intendentes pro Iglesias en } 1983 \\
\text { a } 10 \text { intendentes pro Cafiero ( } 5 \text { otras } \\
\text { pertenencias) en } 1987\end{array}$ \\
\hline & $\begin{array}{l}\text { Cafiero vs. C. Menem (competencia interna, } \\
\text { 1988) }\end{array}$ & $\begin{array}{l}13 \text { a favor de Cafiero } \\
2 \text { a favor de Menem }\end{array}$ \\
\hline & $\begin{array}{l}\text { C. Menem vs. N. Kirchner vs. Adolfo Rodríguez } \\
\text { Saá (elección presidencial, 2003) }\end{array}$ & $\begin{array}{l}1 \text { a favor de Menem } \\
1 \text { a favor de R. Saá } \\
16 \text { a favor de Kirchner/Duhalde }\end{array}$ \\
\hline & $\begin{array}{l}\text { H. de Duhalde vs. C. de Kirchner (elecciones } \\
\text { legislativas, 2005) }\end{array}$ & $\begin{array}{l}10 \text { intendentes pro Duhalde } \\
7 \text { intendentes pro Kirchner }\end{array}$ \\
\hline $\begin{array}{l}\text { Disputa } \\
\text { Informal }\end{array}$ & $\begin{array}{l}\text { C. Menem vs. E. Duhalde } \\
(1997-1999)\end{array}$ & $\begin{array}{l}5 \text { sobre } 6 \text { jefes comunales menemistas } \\
\text { son desplazados de sus respectivas } \\
\text { intendencias }\end{array}$ \\
\hline \multirow{3}{*}{$\begin{array}{l}\text { Acuerdo } \\
\text { Formal }\end{array}$} & $\begin{array}{l}\text { C. Menem y E. Duhalde (elecciones } \\
\text { provinciales -1991- y generales - 1995). }\end{array}$ & $\begin{array}{l}16 \text { intendentes pro Duhalde } \\
6 \text { intendentes pro Menem }\end{array}$ \\
\hline & $\begin{array}{l}\text { E. Duhalde y N. Kirchner (elecciones } \\
\text { provinciales, candidato a gobernador, F. Solá, } \\
\text { septiembre 2003) }\end{array}$ & $\begin{array}{l}\text { Todos los intendentes con el tándem } \\
\text { Duhalde/Kirchner en apoyo a F. Solá }\end{array}$ \\
\hline & $\begin{array}{l}\text { C. de Kirchner y Daniel Scioli (elecciones } \\
\text { presidenciales y a gobernador, 2007) }\end{array}$ & $\begin{array}{l}\text { Todos alineados con la fórmula } \\
\text { kirchnerista, pero, excepto en } 7 \text {, hubo } \\
\text { varios candidatos a intendentes en } 16 \\
\text { distritos (ver Cuadro } 1 \text { ) }\end{array}$ \\
\hline
\end{tabular}

Fuente: elaboración propia sobre los datos presentados hasta aquí.

34 Francisco Gutiérrez, Darío Díaz Pérez, Darío Giustozi y Fernando Gray, respectivamente. 


\section{CONCLUSIÓN}

El artículo alegó que históricamente el peronismo, desde el Estado, imbrica liderazgo presidencial y partidario, fórmula que en realidad se repite (a veces apelando a un delfín) en las diferentes jurisdicciones en las cuales el peronismo gobierna. Desde esta concepción de la jefatura, se demuestra cómo en el CB el liderazgo estructura al peronismo como organización política, fundando su legitimidad última en el sufragio. Sin embargo, la naturaleza de ese liderazgo cambia con la muerte de su fundador, de ahí que la diferencia entre la jefatura eterna del peronismo bajo Perón y la temporal que la sucede repercute en la conformación partidaria. La mudanza en la naturaleza del liderazgo acompaña una transformación en la lógica de la organización política. Mientras la preservación del partido reclama originalmente aceptar que el líder nunca puede ser reemplazado, en el presente esa salvaguardia asume que los líderes esconden una vida útil y necesariamente van a ser sustituidos. Así mientras el peronismo fundacional sigue una lógica de canonización, el peronismo actual promueve una lógica de rotación.

Sobre esta segunda lógica el artículo prueba cómo se despliega la misma a nivel horizontal, con las disputas y acuerdos entre los aspirantes al máximo liderazgo (del partido y de la nación) y cómo impacta en la relación vertical de estos líderes con los jefes locales del CB. Se dibuja entonces una pirámide que encuentra en la cúspide al liderazgo presidencial, en un punto intermedio emerge la jefatura provincial y más abajo se despliegan los jefes locales. Finalmente, la base de la pirámide, la ciudadanía, debe legitimar las jefaturas del gobierno en las tres instancias. En este diseño radica una de las razones que confiere al peronismo mayor fortaleza en términos de gobernabilidad, representatividad y estabilidad, dada la débil institucionalización del régimen democrático y la preponderancia que en él posee el liderazgo presidencial.

\section{BIBLIOGRAFÍA}

Instituto Nacional de Estadísticas y Censos, INDEC (2003): ¿Qué es el Gran Buenos Aires?, Ministerio de Economía y Producción, Secretaría de Política Económica, http://www.indec.gov.ar, Buenos Aires, agosto.

Amaral, Samuel y Mariano Ben Plotkin (2005): Perón: del exilio al poder, Eduntref, Buenos Aires.

Amaral, Samuel y Susan C. Stokes (comps.) (2005): Democracia Local. Clientelismo, capital social e innovación política en la Argentina, Eduntref, Buenos Aires.

Annunziata, Rocío (2006): “Ni oficialista ni opositor: más acá de la nacionalización de la campaña. La significación del caso moronense", en Isidoro Cheresky (comp.): La política después de los partidos, Prometeo, Buenos Aires.

Arias, María Fernanda (2002): Carisma y Poder. El ascenso de Carlos Saúl Menem a la presidencia de la Argentina (1983-1989), TEMAS, Buenos Aires.

(2004): "Institucionalización partidaria en el justicialismo: la corriente renovadora", Revista SAAP, Vol. 1, No 3, Buenos Aires.

Auyero, Javier (1997): “Evita como Performance. Mediación y resolución de problemas entre los pobres urbanos del Gran Buenos Aires", en Javier Auyero (comp.): ¿ Favores por votos? Estudios sobre clientelismo contemporáneo, Losada, Buenos Aires. 
(2007): La zona gris, Siglo XXI, Buenos Aires.

Badía, Gustavo (2001): "Gobierno Local en el Área Metropolitana. Productividad y Gobierno", en Hugo Cormick (ed.): Manual de Gestión Legislativa Municipal, Instituto del Conurbano, Universidad Nacional de General Sarmiento.

(2001): Tensiones en el proceso de formulación y ejecución de políticas en municipios de la región metropolitana de Buenos Aires, VI Congreso Internacional del CLAD sobre la Reforma del Estado y de la Administración Pública, Buenos Aires, Argentina.

Barry, Carolina (2009): Evita capitana, Eduntref, Buenos Aires.

Bennardis, Adrián (1999): "Gestión Municipal en el Conurbano Bonaerense", en Gustavo Blutman (comp.): Investigaciones sobre Reforma del Estado, Municipios y Universidad, Centro de Investigaciones Administrativas, Facultad de Ciencias Económicas, UBA, Buenos Aires.

Buchrucker, Cristian (1986): Nacionalismo y Peronismo. La Argentina en la crisis ideológica mundial (1927-1955), Sudamericana, Buenos Aires.

Caimari, Lila (2002): "El peronismo y la iglesia católica", en Juan C. Torre: Los años peronistas, Sudamericana, Buenos Aires.

Cavarozzi, Marcelo (2006): Autoritarismo y democracia, Eudeba, Buenos Aires.

Cavarozzi, Marcelo y Juan M. Abal Medina (comps.) (2002): El asedio a la política. Los partidos latinoamericanos en la era neoliberal, Homo Sapiens, Rosario.

Cormick, Hugo (1997): "Algunos Problemas de Gobierno y Gestión en los Municipios del Conurbano Bonaerense", en Daniel G. Delgado (comp.): Hacia un Nuevo Modelo de Gestión Local. Municipio y Sociedad Civil en Argentina, FLACSO-UBA, Buenos Aires.

(2001): "Cambios en la Agenda Pública Municipal", en Hugo Cormick (ed.): Manual de Gestión Legislativa Municipal, Instituto del Conurbano, Universidad Nacional de General Sarmiento.

Cravacuore, Daniel Alberto (2001): El estímulo a la innovación en el gobierno local: reflexiones a partir del análisis de experiencias en municipios bonaerenses, VI Congreso Internacional del CLAD sobre la Reforma del Estado y de la Administración Pública, Buenos Aires.

(2003): Motivaciones para el cambio: un análisis de liderazgos en municipios bonaerenses, VIII Congreso Internacional del CLAD sobre la Reforma del Estado y de la Administración Pública, Panamá.

Cheresky, Isidoro (2004): "Elecciones fuera de lo común. Las presidenciales y legislativas nacionales del año 2003", en Isidoro Cheresky y Jean-Michel Blanquer (comps.): ¿Qué cambió en la política argentina? Elecciones, instituciones y ciudadanía en perspectiva comparada, Homo Sapiens, Santa Fe.

Chiara, M., C. Danani y J. Flic (1997): El fondo de Reparación Histórica del Conurbano Bonaerense: una aproximación institucional, Universidad Nacional de General Sarmiento, Buenos Aires.

De Ipola, Emilio (1987): "La difícil apuesta del peronismo democrático", en José Nun y Juan Carlos Portantiero (comps.): Ensayos sobre la transición democrática en la Argentina, Puntosur.

Doyon, Louise (2002): "La formación del sindicalismo peronista", en Juan Carlos Torre (ed.): Los años peronistas (1943-1955), Sudamericana, Buenos Aires.

Frederic, Sabrina (2004): Buenos vecinos, malos políticos. Moralidad y política en el Gran Buenos Aires, Prometeo, Buenos Aires. 
Gutiérrez, Ricardo (2003): "Peronismo y democracia entre 1983 y 1995", Política y Gestión, Vol. 5, Escuela Política y Gobierno, UNSAM, Ciudad Autónoma.

: De la derrota a la reelección: las transformaciones del peronismo entre 1982 y 1995, Tesis en Maestría en Investigación de las Ciencias Sociales, Facultad de Ciencias Sociales, Universidad de Buenos Aires.

Halperín Donghi, Tulio (2000): Vida y muerte de la República verdadera (1910-1930), Ariel, Buenos Aires.

Hintze, S. (1989): Estrategias alimentarias de sobrevivencia. Un estudio de caso en el Gran Buenos Aires, CEAL, Buenos Aires.

Iñiguez, A. y A. Sánchez (1995): "El conurbano bonaerense y la provincia de Buenos Aires, condensación de la tragedia nacional de la desocupación y la subocupación", Cuaderno de trabajo, № 7, IBAP, Buenos Aires.

James, Daniel (1990): Resistencia e Integración. El peronismo y la clase trabajadora argentina, 19461976, Sudamericana, Buenos Aires.

Jones, Mark (2002): “Una evaluación de la democracia presidencialista argentina: 1983-1995", en Scott Mainwaring y M. S. Shugart (eds.): Presidencialismo y democracia en América Latina, Paidós, Buenos Aires.

Levitsky, Steven (2003): Transforming Labour-Based Parties in Latin America: Argentine Peronism in Comparative Perspective, Cambridge University Press, UK-USA.

(2005): "Crisis and Renovation: Institucional Weakness and the Transformation of Argentine Peronism, 1983-2003", en Steven Levitsky y María Victoria Murillo: Argentine Democracy: The Politics of Institutional Weakness, The Pennsylvania State University Press, University Park, Pennsylvania.

McGuire, James (1997): Peronism without Peron. Unions, Parties, and Democracy in Argentina, Stanford University Press, California.

McKinnon, Moira (2002): Los años formativos del Partido Peronista, Siglo XXI-Instituto Di Tella, Buenos Aires.

Mainwaring, Scott y Matthew Soberg Shugart (comps.) (2002): Presidencialismo y democracia en América Latina, Paidós, Buenos Aires.

Masson, Laura (2004): La política en femenino: género y poder en la Provincia de Buenos Aires, Antropofagia/IDES, Buenos Aires.

Mustapic, Ana (2000): "Oficialistas y diputados: Las relaciones Ejecutivo-Legislativo en la Argentina", Desarrollo Económico, 39.

(2002): “Del partido peronista al partido justicialista. Las transformaciones de un partido carismático", en Marcelo Cavarozzi y Juan M. Abal Medina (comps.): El asedio a la política. Los partidos latinoamericanos en la era neoliberal, Homo Sapiens, Buenos Aires.

Navarro, Marysa (2002): “Evita”, en Juan C. Torre (comp.): Los años peronistas (1943-1955), Sudamericana, Buenos Aires.

O'Donnell, Guillermo (1995): "Delegative Democracy", Journal of Democracy, 5, № 1.

O’Donnell, María (2005): El Aparato. Los intendentes del Conurbano y las cajas negras de la política, Planeta. 
Ollier, María Matilde (2003): “Argentina: Up a Blind Alley Once Again? From an Alliance in the Executive to a Coalition in Parliament", Bulletin of Latin American Research, (22) 2, London.

(2004): "Hacia un patrón argentino de inestabilidad", Estudios Sociales (Revista Universitaria Semestral), № 27, año XIV, segundo semestre, Universidad Nacional del Litoral, Santa Fe.

(2005): "Liderazgo presidencial y jefatura partidaria: entre la confrontación y el pacto (2003-2005)", Temas y Debates, № 10, Año 9, Facultad de Ciencia Política y Relaciones Internacionales, Universidad Nacional de Rosario.

(2005): Golpe o Revolución. La violencia legitimada, Eduntref, Buenos Aires.

Panebianco, Angelo (1982): Modelos de partido, Alianza, Madrid.

Palermo, Vicente y Marcos Novaro (1996): Política y poder en el gobierno de Menem, Norma, Buenos Aires.

Passalacqua, Eduardo (2001): "Problemas, Funciones y Desafíos del Legislativo Municipal", en Hugo Cormick (ed.): Manual de Gestión Legislativa Municipal, Instituto del Conurbano, Universidad Nacional de General Sarmiento.

Persello, Ana Virginia (2007): Historia del radicalismo, Edhasa, Buenos Aires.

Potash, Robert (1980): El ejército y la política en la Argentina 1945-1962, Sudamericana, Buenos Aires.

Pucciarelli, Alfredo (coord.) (2006): Los años de Alfonsín ¿El poder de la democracia o la democracia del poder?, Siglo XXI Editores, Buenos Aires.

Quiroga, Hugo (2005): La Argentina en emergencia permanente, Edhasa, Buenos Aires.

Recalde, Aritz (2009): Autonomía o Autarquía en las municipalidades bonaerenses, Editorial Koyatun, Buenos Aires.

Rocca Rivarola, María Dolores: “La Matanza: avatares de la continuidad asegurada. Peronismo, partidos opositores y organizaciones piqueteras", en Isidoro Cheresky (comp.): La política después de los partidos, Prometeo, Buenos Aires.

Rock, David (2001): El radicalismo argentino, 1890-1930, Amorrortu Editores, Buenos Aires.

Rouquie, Alain (1978): Poder militar y sociedad política en la Argentina 1943-1973, Emecé, Buenos Aires.

Sidicaro, Ricardo (2002): Los tres peronismos. Estado y poder económico, 1946-55/1973-76/1989-99, Siglo XXI, Argentina.

Sigal, Silvia y Eliseo Verón (1986): Perón o Muerte. Los fundamentos discursivos del fenómeno peronista, Legasa, Buenos Aires.

Smulovitz, Catalina (1988): Oposición y gobierno: los años de Frondizi, Centro Editor de América Latina, Tomos 1 y 2, Buenos Aires.

Tedesco, Laura (1999): Democracy in Argentina. Hope and Disillusion, Cass, London.

Torre, Juan Carlos (1983): Los sindicatos en el gobierno 1973-1976, Centro Editor de América Latina, Buenos Aires.

(1990): Perón y La vieja guardia sindical. Sobre los orígenes del peronismo, Sudamericana, Buenos Aires.

(1999): "El peronismo como solución y como problema", en Juan Carlos Torre y otros: Entre el abismo y la ilusión. Peronismo, democracia y mercado, Ed. Norma, Buenos Aires. 
(2002): Los años peronistas, 1943-1945, Sudamericana, Buenos Aires.

Tucker, Robert (1970): "The Theory of Charismatic Leadership", en D. Rustow (ed.): Philosopher and Kings: Studies in Leadership, Braziller, New York (citado por Panebianco, Ob. cit.).

Waldman, Peter (2009): El peronismo, Eduntref, Buenos Aires.

Zanatta, Loris (1999): Perón y el Mito de la Nación Católica. Iglesia y Ejército en los orígenes del peronismo, 1943-1946, Sudamericana, Buenos Aires. 